\title{
Citizen Awareness of the Smart City: A Study of Khon Kaen, Thailand
}

\author{
Peerasit KAMNUANSILPA ${ }^{1}$, Sirisak LAOCHANKHAM ${ }^{2}$, Charles David CRUMPTON ${ }^{3}$, John DRAPER ${ }^{4}$ \\ Received: May 05, 2020 Revised: May 17, 2020 Accepted: June 07, 2020
}

\begin{abstract}
Using primary data collected through semi-structured interviews conducted during February 2019, this article examines citizen's awareness and knowledge of Khon Kaen Smart City (KKSC) among the residents of five contiguous municipalities within Khon Kaen Province, Thailand. A self-weighted sample of 420 respondents was selected through a two-stage, 30-cluster sampling process. In the first stage, a sample of 30 artificial clusters of 100 households each was selected. In the second, 14 households were randomly selected from each of these clusters. The head of household or, if unavailable, a resident aged 18 or over was interviewed. The study applies the "citizens as democratic participants" dimension of Simonofski et al.'s (2019) evaluative framework. Results found that, because of ineffective citizen engagement, the levels of awareness and knowledge about KKSC were low. However, multiple logistic regression found that, despite the low levels of awareness and knowledge, education and income could establish an independent effect on awareness of KKSC. Those who completed postsecondary school were more aware of KKSC than those who finished only secondary or primary education. Similarly, the analysis of data clearly indicated that educational attainment, solely and independently from all other socio-economic and demographic variables, could explain the positive effect of education on knowledge about KKSC.
\end{abstract}

Keywords: Smart City, Citizen Engagement, Khon Kaen, Thailand

JEL Classification Code: L32, O21, R42

\section{Introduction}

The Thai government advocates the smart city concept as one of the strategies for moving Thailand ahead under the aegis of the Thailand 4.0 initiative. We feel that the lessons learned by this study of citizen awareness can be generalized over many, if not most, local jurisdictions embarking on their own smart city initiatives.

${ }^{1}$ First Author and Corresponding Author. Dean, College of Local Administration, Khon Kaen University, Thailand [Postal Address: 123 Mitraphab Road, Muang Khon Kaen 40002 Thailand] Email: peerasit@kku.ac.th

${ }^{2}$ Associate Dean for Administrative Affairs, College of Local Administration, Khon Kaen University, Thailand.

${ }^{3}$ Senior Research Associate, Institute for Governmental Service and Research, University of Maryland, College Park, USA.

${ }^{4}$ Assistant Professor, College of Local Administration, Khon Kaen University, Thailand.

(c) Copyright: The Author(s)

This is an Open Access article distributed under the terms of the Creative Commons Attribution Non-Commercial License (http://Creativecommons.org/licenses/by-nc/4.0/) which permits unrestricted noncommercial use, distribution, and reproduction in any medium, provided the original work is properly cited.
Key business and community leaders, mainly in Khon Kaen municipality, capitalized on this policy initiative and advocated for public-private partnerships. Since their assumption was that what they would be doing would be responsive to the needs of the citizens, little promotion was done nor information disseminated to create an awareness of the benefits of smart city for the citizens, in general. This article hypothesizes that, in the absence of an effective information, education, and communication program, the level of awareness of the smart city among the citizens of Khon Kaen will be low.

\section{Study Setting}

\subsection{Khon Kaen Smart City Initiative}

As part of the Thailand 4.0 initiative and as a strategy to improve the quality of life in urban centers, Thailand has set a target of creating 100 smart cities by 2040 (Prathombutr, 2019). To achieve this target, the Thai government set up the National Smart City Committee (NSCC), comprised of a Deputy Prime Minister as the Chairman, the Ministers of Transportation, Digital Economy and Society, Energy, along 
with the Permanent Secretaries from ten related ministries. In addition, high-ranking officials from several relevant agencies and various experts are included, with the Director of the Digital Economy Promotion Agency (DEPA), the Director of the Bureau of Transport and Traffic Systems Development, and the Director of the Office of Energy Policy and Planning forming a co-secretariat (Prime Minister's Office, 2019). Three pilot smart cities were selected for the national initiative: Chiang Mai, Khon Kaen, and Phuket (Naprathansuk, 2017). Subsequently, four more cities were added: Chachoengsao, Chonburi, Rayong, and Bangkok (Nimmanphatcharin, 2017; Prathombutr, 2019). The current study focuses on the experience of Khon Kaen.

With the exception of Khon Kaen, all Thailand's designated smart cities are under the oversight of the DEPA. As compared to the other smart cities included in the national program, Khon Kaen's smart city initiative (KKSC) is a product of local activism involving local business and civic leaders rather than central decision-making. For advocates of public participation in policy making, the local organic nature of KKSC offers hope for greater public engagement in and support for the policy. This study considers whether this hope has been translated into effective citizen engagement and 'ownership' in KKSC.

\subsection{Shifting Away from Historic Thai Administrative Patterns}

The development of Khon Kaen's smart city initiative cannot be considered apart from the highly bureaucratic, topdown administrative approach that has been the historical norm in Thailand (Clarke et al., 2007; Kamnuansilpa et al., 2012). The smart city is intended to be a shift toward a people-centric orientation in public-service provision (Xu \& Geng, 2019). According to this model, KKSC will likely fail if citizen participation and engagement is not included in its design and implementation (Cortés-Cediel et al., 2019; Choque et al., 2019; Bolívar 2019; Simonofski et al., 2019).

The success of Thailand's smart cities has generally been assessed in terms of the amount of money invested and the extent of commitment of central government technical support (Taweesaengsakulthai et al., 2019). However, in the case of Khon Kaen, governmental, business, and community leaders have exhibited different values in their smart city focus. They view it as a governance platform that dramatically diverges from their past experiences with the national bureaucracy, which lacked local orientation and was not responsive to citizens' needs. They seek a break from the centralized management of the country that has been a stumbling block for solving local problems outside of Bangkok (Kamnuansilpa \& Suttipongpracha, 2016). To address this problem, in 2013 Khon Kaen business leaders formed a non-profit private company, the Khon Kaen Think Tank (KKTT), to identify locally generated solutions to local problems (Taweesaengsakulthai et al., 2019; TERRABKK, 2017).

KKTT, in collaboration with the Mayor of Khon Kaen Municipality (KKM), the Khon Kaen provincial governor, and other community leaders, generated the idea of KKSC. Beginning with a proposed light rail train (LRT), Khon Kaen's leaders sought policy rather than financial support from the national government. This resulted in Prime Minister Prayut Chan-o-cha, as Head of the National Council for Peace and Order, endorsing the LRT in 2016. After this endorsement, KKTT and civic groups began an outreach initiative to the citizens of the five municipalities that would be served by the LRT. Relying mainly on the media, the intent was to promote the project to gain acceptance and support from the public sector and local residents (e.g. NewsNBT THAILAND, 2018; Smart-Cities Clean Energy, 2017). These promotional efforts tended to be very broad, academic, and did not focus on the benefits of the smart city or LRT to citizens. This article assesses these citizen engagement activities in terms of evaluative criteria associated with effective citizen engagement in smart cities.

\subsection{The Smart City and Citizen Engagement}

The smart city model of urban planning and management has become a ubiquitous feature of global urban discourse. Fernandez-Anez (2016) has described the smart city as "...a system that enhances human and social capital wisely using and interacting with natural and economic resources via technology-based solutions and innovation to address public issues and efficiently achieve sustainable development and a high quality of life..." (135). "Smart city" is both an aspirational and evaluative descriptor. In terms of urban governance aspiration, cities have been described as aspiring to be "smart" if they seek to use technology to monitor and integrate operation of their infrastructure, including that which supports transportation, energy provision, communications, water production and disposal, and other elements of environmental protection. The aspiring smart city uses technology to plan and support other elements of urban service provision including security and maintenance (Hall et al., 2000). In a conscious effort to create a diverse, inclusive, and sustainable urban environment, the city that aspires to be smart will be conscious in its efforts to make use of ICT to leverage collective urban intelligence by connecting physical, IT, social, and business infrastructures (Cities Today, 2016; Toppeta, 2010).

The most broadly accepted model of the smart city considers six key "smart" dimensions: economy, mobility, environment, people, education, and governance (Cohen, 
2013). The smart city purports to support "smart people" by encouraging participation, inclusiveness, and creativity. "Smart people" values include plural participation and openmindedness. In the smart city, "smart people" are engaged in "smart governance," which involves strengthening connections, interactions, and governance partnerships among city government and stakeholders, including citizens and civil society. The current study considers the extent to which KKSC is realizing these smart city aspirations.

Jacobson and Choi (2008) argued that the more aware citizens are of public projects, the more likely they will be to engage in providing useful input and feedback for service production and delivery. They suggested public workshops, open forums, community meetings, and press conferences as strategies to better educate and engage citizens in proposed public services. The smart city should reflect citizens' needs and views on the rationale for a smart city, thus providing incentives for usage, participation, and feedback for its services. Smart cities should respect citizens-asservice-users who can provide useful input and feedback on the public-private partnerships that underpin the KKSC approach, particularly as they are directly affected by the quality of these services (Jacobson \& Choi 2008; Perng, 2018; Veselitskaya et al., 2019).

\subsection{Evaluating Smart City Citizen Engagement}

Although people and their roles in the governance of smart cities are considered to be essential to smart city planning and operation, citizen participation has received less attention in the international discourse than technological innovation, infrastructure development or other smart city characteristics (Simonofski et al., 2019). Simonofoski et al. argue that inadequate consideration of citizen involvement has resulted in some smart city initiatives not meeting their objectives. Beyond its importance in ensuring that smart cities represent democratic values, citizen participation is essential to providing intelligence needed to assure that smart city solutions are designed to accurately address problems in public service provision with the best available solutions. This study addresses this deficiency in the international discourse regarding the importance of citizen engagement.

As a result of their assessment of the importance of citizen engagement to affect smart city design and implementation and inadequate consideration of it in the smart city discourse, Simonofski et al. offer an evaluative framework to assist in guiding citizen engagement in smart cities and assessing whether citizens have been adequately engaged in smart city processes. The current study will utilize this framework to consider the case of KKSC.

Simonofski et al.'s evaluative framework considers three dimensions of citizen engagement with the smart city: citizens as democratic participants, citizens as cocreators, and citizens as ICT users. They offer an evaluative tool, "CitiVoice," to assess the smart city's performance in these dimensions. Citizens as co-creators and as ICT users apply to smart city implementation and operation, but the case of KKSC only involves the planning phase, so only the dimension of citizens as democratic participants will be utilized to assess the case of Khon Kaen. Simonofski et al., describe this evaluative dimension in terms of three categories and supportive criteria. For the current study some criteria have been collapsed into a reduced number to facilitate ease of application. The methods identified to support the evaluative criteria also have been modified to better fit the current study's setting.

\subsection{Citizens as Democratic Participants}

This dimension considers citizens as direct participants in smart city decision-making. It assesses the substantiveness of opportunities to participate, the representativeness of the citizens allowed to participate, and the impact of the participation. Citizens as democratic participants in a smart city strategy can be evaluated on the following categories and criteria:

- Citizen selection. This category considers the substantiveness of opportunities citizens are offered to participate.

- Representativeness of participants - Citizens involved in the participative processes should be sufficiently representative of the population that will be served by the smart city components.

- Offering of support for the participation process - The support for direct participation might be best provided by an e-voting system. Other alternatives might include facilitation for citizen participation in public meetings where key smart city decisions are considered.

- $\quad$ Agreement on the goals of the smart city strategy. This category considers the substantiveness of the results of citizen participation.

- Citizen are given the opportunity to propose goals and objectives

- Evidence that citizens helped to define goals and objectives

- Correlation between participation activities and achievement of goals. This category considers whether citizen input has been actualized in formal smart city plans.

0 Formalization and transparency of the course of action

- Evidence of interaction between citizens and other actors

- Evidence of the influence of citizens' input in priority setting of smart city projects 


\subsection{Citizen Engagement in Khon Kaen's Smart City Initiative}

This study is supported by a survey that assessed the levels of citizen awareness and knowledge of KKSC in its five constituent municipalities. By emphasizing its value in reducing travel time within the urban region, the LRT project was part of a strategy deployed by KKSC leadership to build citizen support for the broader idea of the smart city. One of the purposes of the survey was to determine the extent of citizen understanding of and support for the LRT project. While the project received buy-in from national leaders, the provincial governor, local mayors, and business leaders, ordinary citizens did not have a major voice in LRT planning. Furthermore, the researchers assumed that the concept of the smart city is obscure to many citizens, contrasting with the generally accepted idea in the smart city discourse that all smart cities must be inclusive and actively engage with citizens. While LRT may have been successfully implemented and pleased its users, without sufficient information from those who should benefit from the smart city the broader KKSC may not improve their lives. Unintended consequences might actually reduce the quality of life for many citizens. For instance, gentrification that often accompanies mass transit development (Padeiro et al., 2019) may be a disadvantage to some of the most vulnerable in the Khon Kaen urban region.

Some lack of understanding concerning the meaning of the smart city in Thailand is linguistic in nature. "Smart city" is not well-defined in Thai. The very word "smart" is difficult to translate into Thai. "Smart city" literally translates as "genius city." This carries a connotation that the projects pursued or services provided exist in a highly intellectual manner, by and/or for geniuses or prodigies. According to these terms, ordinary people might feel alienated or excluded. This is further complicated by the fact that the smart city concept has evolved through different names in Thailand (Taweesaengsakulthai et al., 2019). Thus, citizen awareness of and knowledge about the smart city in Khon Kaen should not be taken for granted by KKSC promoters.

From its historic top-down and Bangkok-centric perspective (Kamnuansilpa et al., 2014), Thailand's government, as with much of its public-policy formulation and implementation, assumed citizen support as a given for its smart city policy. Its policy approach emphasizes digital technology and infrastructure development, with little emphasis on citizen involvement to develop awareness and knowledge of the purported benefits of a smart city. In the case of KKSC, the smart city idea originally emerged from the vision of a group of local business leaders to solve the acute problem of traffic congestion. Despite the admirable intent of KKTT, consistent with the perspective of the Thai central government, their view of citizens may be assessed as paternalistic or elitist (Cardullo \& Kitchin, 2019), with citizens considered as only beneficiaries of KKSC and not participants in its planning. Again, this stands in contrast to the general international smart city discourse that posits citizen participation in the smart city's planning is prominent in its success (Myeong et al., 2018; Rašić et al., 2018).

Existing research in Thailand offers support for the need to address citizen engagement in smart city development. A 2017 study examined smart city awareness in Nonthaburi Province, which was not designated as host to a smart city by the Thai government (Angsukanjanakul, 2017). This research found low citizen awareness and knowledge of smart cities. Thus, while citizen engagement is essential to the success of any smart city, we argue that, in Thailand in particular, assessing smart city awareness and knowledge is a prerequisite for not only the acceptability but also for the success of smart city development.

\section{Methodology}

This study considers citizen awareness of the smart city concept by assessing citizen responses to a central, straightforward question: "Have you ever heard about smart cities?" The extent of citizen smart city knowledge and awareness was further assessed by posing two additional questions: "Do you know what constitutes a smart city?" Those who answered "yes" were also asked, "What are the components of a smart city?" The respondent's smart city knowledge was compared against the six components of Cohen's (2013) smart city wheel employed by the KKSC: smart economy, smart environment, smart governance, smart living, smart mobility, and smart people. Because smart city is not a typical topic of conversation among citizens, unprompted and prompted questions were used. Thus, for respondents who could identify some of the six smart city components, interviewers read the components that were not initially identified. For respondents who could not identify any components, interviewers read all six components to determine if the respondents could confirm that any of them comprised a smart city, whether they had heard of them in the context of Khon Kaen, and what they knew about them.

Primary data were collected through semi-structured interviews conducted during February 2019. A nonreplacement random sample of 30 clusters was used that represented an equal probability of any given household in the five KKSC municipalities. This was implemented through a two-stage, 30 -cluster sampling process to select 420 respondents for interviews. In the first stage, 30 clusters were selected. In the second, 14 households were randomly selected from each selected cluster to interview the head of household or, if unavailable, a resident aged 18 or over. In effect, this was a self-weighted sample design that adjusted for the differences in the size of the municipalities. The intent of the design was to ensure that the margin of error was less than $+/-10$ per cent and a confidence level of 95 per cent. 
Table 1: Sampling structure, by municipality (In subsequent tables, these are consolidated into three categories based on population)

\begin{tabular}{|l|c|c|c|c|c|c|}
\hline Municipality & $\begin{array}{c}\text { Number of } \\
\text { households }\end{array}$ & $\begin{array}{c}\text { Number of } \\
\text { clusters }\end{array}$ & $\begin{array}{c}\text { Clusters as } \\
\text { proportion } \\
\text { of total }\end{array}$ & $\begin{array}{c}\text { Number of } \\
\text { clusters } \\
\text { selected }\end{array}$ & $\begin{array}{c}\text { Identification of } \\
\text { selected clusters }\end{array}$ & $\begin{array}{c}\text { Number of } \\
\text { respondents }\end{array}$ \\
\hline Khon Kaen & 24,790 & 247.9 & 0.342 & 10.2 & $\begin{array}{c}9,34,40,43,52,84, \\
102,116,120,173,242\end{array}$ & 143 \\
\hline Sila & 25,227 & 252.3 & 0.348 & 10.4 & $\begin{array}{c}44,52,74,77,112,119, \\
142,157,201,217,237\end{array}$ & 146 \\
\hline Mueang Kao & 15,573 & 155.7 & 0.215 & 6.4 & $\begin{array}{c}11,21,60,78,98, \\
122,140\end{array}$ & 90 \\
\hline Thaphra & 3,786 & 37.9 & 0.052 & 1.6 & 6,23 & 22 \\
\hline Samran & 3,183 & 31.8 & 0.044 & 1.3 & 9,13 & 18 \\
\hline Total & $\mathbf{7 2 , 5 5 9}$ & $\mathbf{7 2 5 . 6}$ & $\mathbf{1 . 0 0 0}$ & $\mathbf{3 0}$ & & 420 \\
\hline
\end{tabular}

Sampling statistics on the numbers of households in each municipality were used to create the clusters of households. As seen in Table 1, there were a total of 72,559 households in the five municipalities that, when the sampling approach was administered, resulted in a total of 725.6 clusters. The second column shows the number of households per municipality. The third shows the number of clusters per municipality, referenced again in the fourth column as a proportion of the total clusters (725.6) of all five municipalities. Column five shows the number of clusters selected from each municipality. The sixth column shows the randomly selected clusters. The final sampling step was to randomly select 14 households within each cluster to be interviewed. The average interview duration was 30 minutes.

\section{Results}

The results of the interviews with the 420 respondents are divided into five subsections. The first provides a description of the characteristics of the process. The second offers a general picture of the level of citizen awareness of smart cities. The third shows the level of citizen knowledge of smart cities. The fourth analyzes the demand for LRT among the respondents. The fifth considers awareness and knowledge using a multivariate statistical technique to assess which variables had independent effects on the levels of citizen awareness and knowledge of smart city concepts.

The sample was comprised of $260 \quad(61.9 \%)$ females and $160(38.1 \%)$ males, a gender ratio of 61.6 men per 100 women. This is far below the rate for the five municipalities of 90.6 men per 100 women. The over representation of women likely results from men working outside the home and not available for the interview. Another likely factor is that a number of women participants are single heads of household.

\subsection{Awareness of Smart Cities}

Survey respondents demonstrated a low level of awareness about smart cities. The question for awareness was, "Have you ever heard of the term 'smart city'?" In terms of age, the respondents were classified into four groups: 105 (25\%) were $18-34 ; 116(27.6 \%)$ were $35-49 ; 103$ (24.5\%) were 50-59; and 96 (22.9\%) were over 60. Regarding educational attainment, the respondents were classified into three levels: primary, 120 (28.6\%); secondary, 141 (33.6\%); and post-secondary, 159 (37.9\%). The respondents were further classified according to two employment type groups: employed and self-employed. The number of those who selfidentified as employed outside of their residences totaled $128(30.5 \%)$. Those who self-identified as self-employed and could be working anywhere, including their homes, totaled $292(69.5 \%)$. Respondents were also categorized into three marital status groups: $261(62.1 \%)$ were married; $57(13.6 \%)$ were divorced or separated; and 102 were single $(24.3 \%)$. Regarding monthly income, 151 (36.0\%) reported an income of 9,000 baht (USD296.66 exchange rate as of 19 February 2020) or less, while 119 respondents (28.35) reported income of between 9,001 and 15,000 baht (USD494.43), and 150 respondents (35.7\%) reported income of over 15,000 baht.

The results from a bivariate analysis using the chi-square test are shown in Table 2. No significant difference was found in citizen awareness by gender, employment type, or marital status, while the level of awareness increased slightly as the level of educational attainment and income increased. Young respondents (18-34 years) and older respondents (60 and above) were less likely to be aware of smart cities.

When respondents were asked if municipal officials had informed them of plans to develop their municipality into 
a smart city, $360(85.7 \%)$ responded "no." Among the 60 (14.3\%) who responded 'yes,' the message that they received was not about the overall KKSC scheme. Rather, it was about the proposed plan for LRT construction. At the time of the survey, KKSC was focused on smart mobility, with the KKSC promotional material emphasizing the benefits of LRT. To assess the effectiveness of KKSC promotional material, respondents were questioned regarding their awareness of the eminence of LRT. A substantial majority
(84\%) of respondents were aware of the planned LRT project.

Bivariate relationships were calculated between demographic variables and awareness of smart cities (Table 2). There were no statistically significant differences among the three categories of municipalities. This can be interpreted as all five municipalities being equally ineffective in their attempts to create awareness of the general concept of smart cities and of KKSC in particular.

Table 2: Percentages of respondents aware of smart cities, by demographic characteristics.

\begin{tabular}{|c|c|c|c|}
\hline Demographic characteristic & Number & $\%$ & P-value \\
\hline Name and type of municipality & & & 0.945 \\
\hline $\begin{array}{l}\text { Nakorn: city municipality (population of } 50,000+\text { and sufficient income to } \\
\text { function as a city) }\end{array}$ & 72 & 50.3 & \\
\hline $\begin{array}{l}\text { Muang: town municipality (either a provincial capital or a population of } 10,000+ \\
\text { and sufficient income to function as a town) }\end{array}$ & 73 & 50.0 & \\
\hline $\begin{array}{l}\text { Tambon: subdistrict municipality (gross income of } 5 \text { million baht or more and a } \\
\text { population of } 5,000+\text { with a minimum density of } 1,500 \text { per } \mathrm{km}^{2} \text { ) }\end{array}$ & 68 & 51.9 & \\
\hline Gender & & & 0.863 \\
\hline Male & 82 & 51.2 & \\
\hline Female & 131 & 50.4 & \\
\hline Age & & & 0.002 \\
\hline $18-34$ & 53 & 50.5 & \\
\hline $35-49$ & 71 & 61.2 & \\
\hline $50-59$ & 55 & 53.4 & \\
\hline $60+$ & 34 & 35.4 & \\
\hline Education & & & $<0.001$ \\
\hline Primary & 39 & 32.5 & \\
\hline Secondary & 70 & 49.6 & \\
\hline Post-Secondary & 104 & 65.4 & \\
\hline Employment type & & & 0.197 \\
\hline Employed & 71 & 55.5 & \\
\hline Self Employed & 142 & 48.6 & \\
\hline Marital status & & & 0.512 \\
\hline Married & 131 & 50.2 & \\
\hline Divorced/Separated & 26 & 45.6 & \\
\hline Single & 56 & 54.9 & \\
\hline Income & & & $<0.001$ \\
\hline 9,000 and less & 54 & 35.8 & \\
\hline $9,001-15,000$ & 69 & 58.0 & \\
\hline $15,000+$ & 90 & 60.0 & \\
\hline Total & 213 & 50.7 & \\
\hline
\end{tabular}




\subsection{Knowledge of Smart Cities}

In the current study, the meaning of knowledge as compared to that of awareness focuses on information that respondents have acquired from any source, including personal experience, media sources, other persons, and the organizations responsible for planning and implementing KKSC. In the analysis of respondent knowledge of one or more components of smart cities, it was found that respondents' knowledge of smart cities was, as with the awareness dimension, low. Even with prompting regarding smart city components, only $35.0 \%$ of the respondents were able to name at least one component of smart cities. The average number of components identified by respondents was less than one (0.85). Knowledge about smart cities might be inflated by the coding scheme used. For example, $30.5 \%$ of respondents identified light rail train, which was coded as knowledge about smart mobility. Similarly, those who identified education were classified as knowing about smart people. Additionally, those who identified using digital technology to improve the economy, employment types, and/ or income generation were coded as knowing about smart economy. Despite this liberal coding, respondent knowledge of smart cities was still low.

Table 3: Knowledge of at least one smart city component, by demographic characteristic.

\begin{tabular}{|c|c|c|c|c|c|c|}
\hline \multirow{2}{*}{ Characteristics } & \multirow{2}{*}{$\begin{array}{l}\text { Number of } \\
\text { respondents }\end{array}$} & \multicolumn{2}{|c|}{$\begin{array}{l}\text { Know at least one } \\
\text { component }\end{array}$} & \multicolumn{3}{|c|}{ Number of known components } \\
\hline & & $\%$ & P-value & Mean & SD & P-value \\
\hline Municipality & & & 0.678 & & & 0.744 \\
\hline Nakorn & 52 & 36.4 & & 0.90 & 1.503 & \\
\hline Muang & 47 & 32.2 & & 0.87 & 1.528 & \\
\hline Tambon & 48 & 36.6 & & 0.77 & 1.333 & \\
\hline Gender & & & 0.674 & & & 0.891 \\
\hline Male & 58 & 36.3 & & 0.86 & 1.443 & \\
\hline Female & 89 & 34.2 & & 0.84 & 1.471 & \\
\hline Age & & & 0.008 & & & 0.019 \\
\hline $18-34$ & 34 & 32.4 & & 0.67 & 1.238 & \\
\hline $35-49$ & 55 & 47.4 & & 1.16 & 1.604 & \\
\hline $50-59$ & 33 & 32.0 & & 0.91 & 1.603 & \\
\hline 60 and above & 25 & 26.0 & & 0.60 & 1.269 & \\
\hline Education & & & $<0.001$ & & & 0.004 \\
\hline Primary & 23 & 19.2 & & 0.52 & 1.250 & \\
\hline Secondary & 47 & 33.3 & & 0.85 & 1.468 & \\
\hline Post-Secondary & 77 & 48.4 & & 1.10 & 1.552 & \\
\hline Employment status & & & 0.110 & & & 0.040 \\
\hline Employed & 52 & 40.6 & & 1.07 & 1.623 & \\
\hline Self Employed & 95 & 32.5 & & 0.75 & 1.373 & \\
\hline Marital Status & & & 0.849 & & & 0.574 \\
\hline Married & 90 & 34.5 & & 0.79 & 1.346 & \\
\hline Divorced/Separated & 19 & 33.3 & & 0.98 & 1.674 & \\
\hline Single & 38 & 37.3 & & 0.92 & 1.609 & \\
\hline Income & & & 0.006 & & & 0.071 \\
\hline 9,000 and less & 39 & 25.8 & & 0.65 & 1.362 & \\
\hline $9,001-15,000$ & 43 & 36.1 & & 0.87 & 1.406 & \\
\hline 15,000 and above & 65 & 43.3 & & 1.03 & 1.573 & \\
\hline Total & 147 & 35.0 & & 0.85 & 1.459 & \\
\hline
\end{tabular}


The participants were asked, "What are the components of a smart city?" The responses were derived in two steps. First, respondents were asked if they knew of any of the components of smart city. Then they were then prompted concerning whether they knew of each of the six smart city components (see Table 3).

Similar to awareness, no significant difference was found by municipality size. There were statistically significant differences by age, education, and employment status. Respondents aged 18 to 34 and those 60 and over knew less about smart cities than those aged 35 to 59 years. The level of knowledge increased with educational attainment. In terms of employment type, those who were employed and worked outside of their homes knew more about smart cities than those who were self-employed, perhaps because they interacted more with other people. There were no significant differences by gender, marital status, or income.

\subsection{Demand for LRT}

The primary focus of the KKSC program was strictly on LRT, not smart mobility in general terms. Consequently, demand for LRT was assessed through two questions asked of all respondents: "Do you want LRT to run through your community?" and "Do you think your fellow citizens in your community want LRT to run through the community?"

Approximately three quarters of respondents answered "yes" to both questions. Despite a widespread lack of awareness and knowledge of smart cities, there exists a substantial demand for LRT among citizens of the five municipalities. This may be related to more generalized knowledge of and frustration with the urban region's traffic congestion problems than with any association with KKSC.

\subsection{Multivariate Analysis of Awareness of and Knowledge about Smart Cities}

As the preceding subsections indicate, differences in awareness and knowledge of smart cities cannot be attributed to the size or type of municipality. Differences are largely associated with individual respondent characteristics. The following discussion considers the effects of age, education, and income on awareness of smart cities, and the effects of age, education and employment type on knowledge of smart cities. Multiple logistic regression was applied to establish the effects of age, education, and income on awareness of smart cities. A preliminary run was conducted using backward elimination to conduct an initial analysis. A logistic regression model was derived to assess the statistically significant independent effects of each variable. After the initial run, age was removed from the model. As represented in Table 4, only education and income were retained in the final multiple logistic regression model. Examination of both unadjusted and adjusted Odd Ratios (OR) reveals that citizen awareness increases and varies directly by educational attainment. As levels of income increase, so do levels of citizen awareness of smart cities. As education and income may be reinforcing each other, more attention should be paid to the values of the adjusted OR.

Based on the adjusted OR, awareness of smart cities among respondents who had completed secondary school was $77 \%$ higher than for those who had only completed primary school. Among those who had post-secondary

Table 4: Final multivariate analysis model for awareness of smart cities

\begin{tabular}{|c|c|c|c|c|c|c|}
\hline Variable & $(\mathrm{N})$ & $\begin{array}{c}\% \text { of } \\
\text { awareness }\end{array}$ & $\begin{array}{l}\text { Unadjusted } \\
\text { OR (95\% CI) }\end{array}$ & P-Value & $\begin{array}{l}\text { Adjusted OR } \\
(95 \% \mathrm{Cl})\end{array}$ & P-Value \\
\hline \multicolumn{7}{|l|}{ Education } \\
\hline Primary & 120 & 32.50 & 1 & & 1 & \\
\hline Secondary & 141 & 49.65 & $\begin{array}{c}2.05 \\
(1.24-3.39)\end{array}$ & 0.005 & $\begin{array}{c}1.77 \\
(1.04-2.99)\end{array}$ & 0.034 \\
\hline Post-Secondary & 159 & 65.41 & $\begin{array}{c}3.93 \\
(2.38-6.49)\end{array}$ & $<0.001$ & $\begin{array}{c}3.20 \\
(1.82-5.64)\end{array}$ & $<0.001$ \\
\hline \multicolumn{7}{|l|}{ Income } \\
\hline$<=9,000$ & 151 & 35.76 & 1 & & 1 & \\
\hline $9,001-15,000$ & 119 & 57.98 & $\begin{array}{c}2.49 \\
(1.51-4.06)\end{array}$ & $<0.001$ & $\begin{array}{c}2.06 \\
(1.24-3.44)\end{array}$ & 0.006 \\
\hline$>15,000$ & 150 & 60.00 & $\begin{array}{c}2.69 \\
(1.69-4.30)\end{array}$ & $<0.001$ & $\begin{array}{c}1.63 \\
(0.96-2.77)\end{array}$ & 0.070 \\
\hline
\end{tabular}


education, awareness of smart cities was 3.2 times higher than those who only had primary education.

To determine the independent effects of income on citizen awareness, a monthly income of no more than 9,000 baht was used as the point of reference. At 2.06 times greater than the reference group, awareness of smart cities among those who earned between 9,000 and 15,000 baht per month was the highest. For those whose monthly income was higher than 15,000 baht, the knowledge level was, interestingly, only 1.63 times greater.

A logistic regression was also applied to test the independent effects of age, education, and employment type on knowledge of smart cities. Using the same procedures and steps as with the awareness dimension, age and employment type were eliminated in the initial run. As represented in Table 5, the result was that only educational attainment could independently and solely explain the variation in knowledge among the respondents.

Using primary education as the point of reference, those who completed secondary school were 2.1 times more likely to possess knowledge of smart city components. Among those with some post-secondary education, this likelihood increased to 4.2 times. One of the reasons a positive relationship was found between educational attainment and knowledge of smart cities was likely because the five municipalities were not actively promoting all components of smart cities to the lower socio-economic sectors.

Table 5: Final multivariate analysis model for knowledge of smart cities

\begin{tabular}{|c|c|c|c|c|c|c|}
\hline Variable & $(\mathrm{N})$ & $\begin{array}{l}\% \text { know at least } \\
\text { one component }\end{array}$ & $\begin{array}{l}\text { Unadjusted } \\
\text { OR }(95 \% \mathrm{Cl})\end{array}$ & P-value & $\begin{array}{c}\text { Adjusted OR } \\
(95 \% \mathrm{Cl})\end{array}$ & P-Value \\
\hline \multicolumn{7}{|l|}{ Education } \\
\hline Primary & 120 & 19.2 & 1 & & 1 & \\
\hline Secondary & 141 & 33.3 & $\begin{array}{c}2.11 \\
(1.19-3.74)\end{array}$ & 0.011 & $\begin{array}{c}2.10 \\
(1.13-3.87)\end{array}$ & 0.018 \\
\hline Post-Secondary & 159 & 48.4 & $\begin{array}{c}3.96 \\
(2.28-6.87)\end{array}$ & $<0.001$ & $\begin{array}{c}4.21 \\
(2.28-7.79)\end{array}$ & $<0.001$ \\
\hline
\end{tabular}

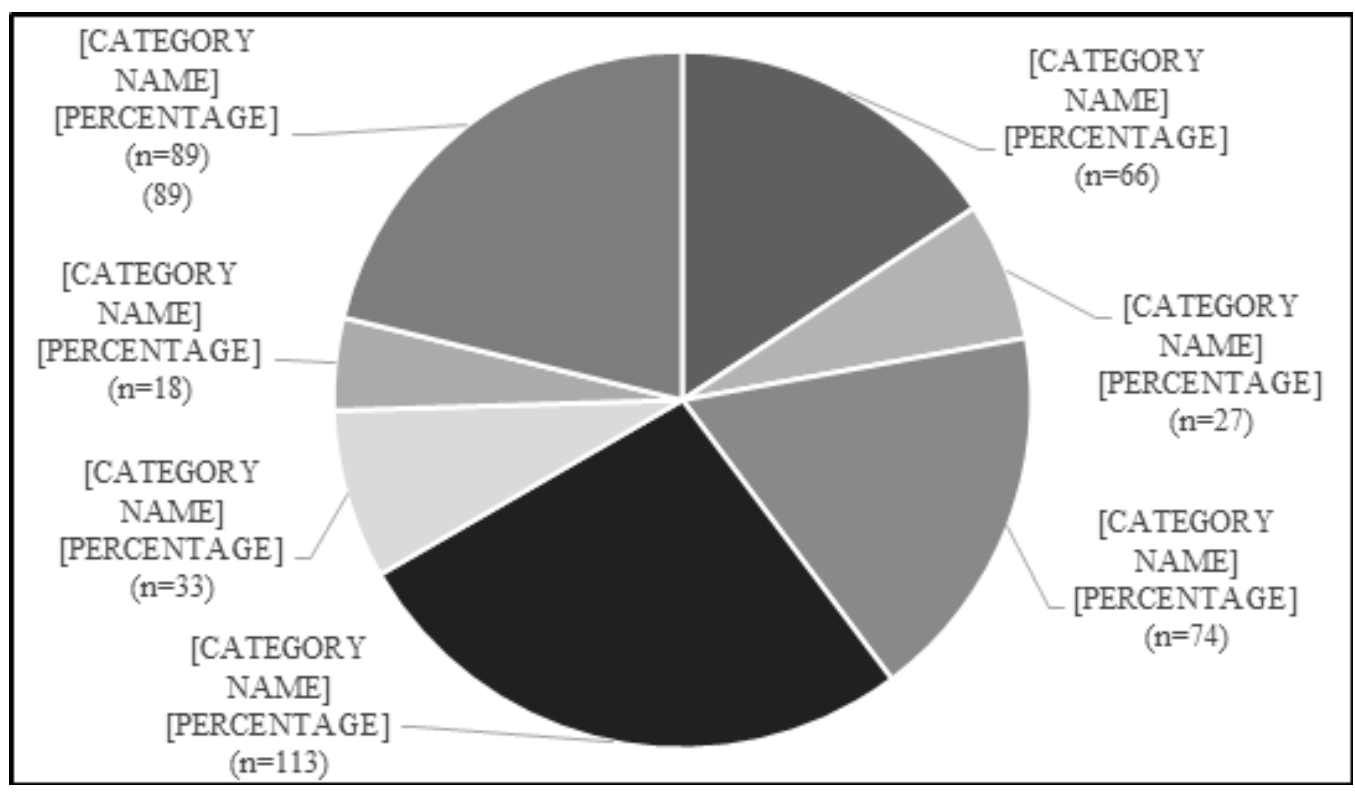

Figure 1: Smart city components most desired by participants 
After informing all respondents of the smart city program components, they were asked which component they would prefer to see implemented first. Even though KKSC's priority is the urban region's traffic congestion problems, a component of mobility, factors that relate to the economic and daily living benefits of smart city are foremost in people's minds (Figure 1).

\section{Discussion and Conclusion}

The survey found that the level of awareness and knowledge of smart cities among the citizens of the five municipalities was low. Even though the plan to transform Khon Kaen into a smart city represented a politically bottom-up approach that involved local business leaders and the mayors of the five municipalities in soliciting policy support from the central government, it did not recognize the significance of local citizen engagement, likely resulting in the evidence of low citizen awareness and knowledge found in the current study. To enhance the understanding and interpretation of the survey's results, they were shared with 10 key informants who are knowledgeable of the promotion of the LRT project but are not directly involved with it. These informants provided additional qualitative data.

These informants were all supporters of KKSC. They understood that low citizen awareness and knowledge was exacerbated by a lack of an effective citizen engagement program. They wanted the construction of the LRT project to start immediately. One informant believed that the LRT's route would not be running through the most congested part of Khon Kaen, thus contributing little to solving traffic problems. Indeed, the proposed route runs outside this area, on a highway with relatively uncongested traffic. A counterargument was that the current city bus system was equipped with digital applications that could easily be adapted to enable buses to become passenger feeders to the LRT. Another contended that when the LRT project was proposed to the central government for policy support, it was not included as a project under the smart city development umbrella, which could have blurred the conceptualization of the KKSC among the respondents.

While the transit system was a locally initiated approach, including support from five municipalities and includes an innovative regional financing approach, given the nature of Thailand's administrative system, its implementation is still subject to approval by Bangkok. Thus, LRT's main obstacle is Thailand's political centralization, which reduces the chances of success. That the LRT plan was formulated by an elite group of leaders in the local business and government sectors with little citizen or wider stakeholder input further threatens its viability.

\section{Applying Simonofski Evaluative Framework}

It is useful to apply the "citizens as democratic participants" dimension of Simonofski et al.'s (2019) evaluative framework to the KKSC experience. They argue that effective engagement with citizens involves three critical process categories:

- Citizen selection that is representative of the population to be served by smart city components and active smart city support for methods of participation available to citizens.

- Agreement on the goals of the smart city strategy, including evidence that citizens helped to define its goals and objectives and that the goals and objectives adopted by the smart city reflect a citizen orientation.

- Correlation between participation activities and achievement of goals, including evidence that citizen input has been incorporated into the prioritization of plans for smart city component implementation.

In the case of $\mathrm{KKSC}$, the evidence indicates that none of the characteristics of the citizen engagement framework proposed by Simonofski et al. (2019) were pursued. What citizen engagement activities were pursued involved promotion of an LRT project that was largely the product of the local elite's identification of a problem and a publicservice approach to address the problem. Citizens were not engaged in problem definition or identification of desirable approaches to solve the problem. Furthermore, the public conversation regarding the potential LRT project was not part of a broader conversation regarding the creation of KKSC and how this "smart mobility" approach fit into the overall priorities of the prospective smart city. In light of this assessment, it is little wonder that citizens of the Khon Kaen urban region demonstrate low awareness and knowledge of smart cities, both in general terms and in relation to the Khon Kaen approach.

This assessment of the KKSC experience within the Simonofski framework might be further understood in terms of a component of the international critical discourse concerning troubling characteristics of the smart city movement. One of the most frequently considered problematic dimensions raised by students of the normalized smart city discourse is that social, political, planning and functional need variables have received too little consideration in smart city planning. Critics from this perspective argue that smart cities have viability only to the extent that they are placed in service of inter-contextual practical priorities. They further argue that identification of the priorities to be pursued through 'smart' approaches should be determined through deliberative approaches that fit local contextual conditions. Such deliberative approaches 
must include the citizens to be impacted through serious and respectful forms of engagement (Vanolo, 2014; Colding \& Barthel, 2017; Andreani et al., 2018). The KKSC experience to date offers no evidence of a deliberative process that effectively engages citizens.

\section{Recommendation}

Pending the approval of central government agencies, Khon Kaen's plans to implement an LRT system and related development could stall indefinitely. Assuming that this project and the Khon Kaen area's business, civic, and governmental leadership's broader smart city ambitions remain viable, the five municipalities involved must engage with citizens to demonstrate citizen demand and to ensure that their smart city programs are responsive to citizens' needs. A deliberative process that embraces the characteristics of citizen engagement identified by Simonofski et al. (2019) should be introduced. As local leaders continue to lobby the central government for approvals needed for implementation of the LRT project and other smart city activities, evidence of effective citizen engagement might help their case. It might also contribute to changing historic patterns of Thai administration to make it more citizen oriented.

\section{References}

Andreani, S., Kalchschmidt, M., Pinto, R., \& Sayegh, A. (2018). Reframing technologically enhanced urban scenarios. Technological Forecasting \& Social Change, 142, 15-25. DOI: 10.1016/j.techfore.2018.09.028

Angsukanjanakul, J. (2017, July). Perception and awareness of Thailand smart city. Presented at the 2017 ICBTS Conference, 10-12 July, Zurich, 2017. Retrieved November 13, 2019, from http://www.ijbts-journal.com/images/column_1502875704/ Tract\%204.pdf

Bolívar, M. P. R. (2019). Public value, governance models and cocreation in smart cities. Public Administration and Information Technology, 35, 271-280. DOI: 10.1007/978-3-319-989532_11

Cardullo, P., \& Kitchin, R. (2019). Being a 'citizen' in the smart city: Up and down the scaffold of smart citizen participation in Dublin, Ireland. GeoJournal, 84(1), 1-13. DOI: 10.1007/ s10708-018-9845-8

Choque, J., Diez, L., Medela, A., \& Muñoz, L. (2019). Experimentation management in the co-created smart-city: Incentivization and citizen engagement. Sensors, 19(2), Article No. 411. DOI: 10.3390/s19020411

Cities Today. (2016, November 2). How EUROCITIES is helping members become smart cities. Retrieved November 13, 2019, from https://cities-today.com/how-eurocities-is-helpingmembers-become-smart-cities/
Clarke, J., Newman, J., Smith, N., Vidler, E., \& Westmarland, L. (2007). Creating Citizen-Consumers: Changing Publics and Changing Public Services. London: Sage.

Cohen, B. (2013). The smart city wheel. Smart Circle. Retrieved November 13, 2019, from https://www.smart-circle.org/ smartcity/blog/boyd-cohen-the-smart-city-wheel/

Colding, J., \& Barthel, S. (2017). Letter to the Editor: An urban ecology critique on the 'smart city' model. Journal of Cleaner Production, 164, 95-101. DOI: 10.1016/j. jclepro.2017.06.191

Cortés-Cediel, M.E., Cantador, I., \& Bolívar, M.P.M. (2019). Analyzing citizen participation and engagement in European smart cities. Social Science Computer Review. DOI: $10.1177 \% 2 F 0894439319877478$

Fernandez-Anez, V. (2016, June). Stakeholders approach to smart cities: A survey on smart city definitions. Conference: International Conference on Smart Cities (pp. 157-167). DOI: 10.1007/978-3-319-39595-1_16.

Hall, R.E., Bowerman, B., Braverman, J., Taylor, J., Todosow, H., \& Wimmersperg, U.V. (2000). The vision of a smart city. 2nd International Life Extension Technology Workshop. Paris, France, September 28, 2000

Jacobson, C., \& Choi, S. O. (2008) Success factors: public works and public-private partnerships. International Journal of Public Sector Management, 21(6), 637-657. DOI: 10.1108/09513550810896514

Kamnuansilpa, P., Wongthanawasu, S., \& Ando, H. (2012). Thailand decentralizes: Local views. Khon Kaen, Thailand: Klung Nana Wittaya.

Kamnuansilpa, P., \& Suttipongpracha, T. (2016). Development of Thai Government Administration: From Past to the Future. Khon Kaen, Thailand: Nana Wittaya.

Myeong, S., Jung, Y., \& Lee, E. (2018). A study on determinant factors in smart city development: An analytic hierarchy process analysis. Sustainability, 10, 2606. DOI: 10.3390/su10082606

Naprathansuk, N. (2017). A national pilot project on smart city policy in Thailand: A case study on Phuket, Khon Kaen, Chiangmai. European Journal of Multidisciplinary Studies, 6(1), 337-346. DOI: 10.26417/ejms.v6i1.p337-346

NewsNBT THAILAND. (2018, May 27). Pushing Khon Kaen towards Smart City. Evening News. Retrieved November 13, 2019, from https://www.youtube.com/ watch? $\mathrm{v}=\mathrm{O} 6 \mathrm{Q} 5 \mathrm{RK} 19 \mathrm{HyA}$

Nimmanphatcharin, N. (2017). Thailand Smart City. Bangkok: DEPA, 2017. Retrieved November 13, 2019, from https:// tinyurl.com/qoom 3 p2

Padeiro, M., Louro, A., \& da Costa, N.M. (2019). Transitoriented development and gentrification: a systematic review. Transport Reviews, 39(6), 733-754, DOI: 10.1080/01441647.2019.1649316

Prathombutr, P. (2019). Smart cities development in Thailand. Bangkok: Ministry of Digital Economy and Society, 2019. 
Retrieved November 13, 2019, from https://www.nstda.or.th/ nac/2019/images/seminar/26_Smartcity_passakorn.pdf

Perng, S. (2018). Promises, practices and problems of collaborative infrastructuring: The case of Dublin City Council (DCC) Beta and Code for Ireland. In C. Coletta, L. Evans, L. Heaphy, \& R. Kitchin (Eds), Creating Smart Cities (pp. 155-168). London, UK: Routledge.

Prime Minister's Office. (2019). National Smart City Committee Announcement of 1/2019. Office of the Prime Minister. Bangkok: The Prime Minister's Office, 2019, Retrieved November 13, 2019, from https://tinyurl.com/rd9zcye

Rašić, M., Milenkovic, M., \& Vojkovic, G. (2018). Smart- cityawareness amongst Croatian citizens. 41st International Convention on Information and Communication Technology, Electronics and Microelectronics, MIPRO 2018 - Proceedings, pp. 1328-1333. New York, NY: IEEE.

Simonofski, A., Serral, E., \& Wautelet, Y. (2019). Citizen participation in the design of smart cities: Methods and management framework. In A. Visvizi \& M.D. Lytras (Eds), Smart Cities: Issues and Challenges: Mapping Political, Social and Economic Risks and Threats (pp. 47-62). Amsterdam: Elsevier.
Taweesaengsakulthai, S., Laochankham, S., Kamnuansilpa, P., \& Wongthanavasu, S. (2019). Thailand smart cities: What is the path to success? Asian Politics \& Policy, 11(1), 144-156. DOI: 10.1111/aspp. 12445

TERRABKK. (2017, September 13). Khon Kaen to Develop Private Smart City. Retrieved November 13, 2019, from https:// tinyurl.com/qmedgen

Toppeta, D. (2010). The smart city vision: How innovation and ICT can build smart, "livable", sustainable cities. The Innovation Knowledge Foundation. Retrieved November 13, 2019, from https://www.inta-aivn.org/images/cc/Urbanism/ background\%20documents/Toppeta_Report_005_2010.pdf

Vanolo, A. (2014). Smartmentality: The smart city as disciplinary strategy. Urban Studies 51(5), 883-898. DOI: $10.1177 / 0042098013494427$

Veselitskaya, N., Karasev, O., \& Beloshitskiy, A. (2019). Drivers and barriers for smart cities development. Theoretical and Empirical Researches in Urban Management, 14(1), 85-110.

Xu, H., \& Geng, X. (2019). People-centric service intelligence for smart cities. Smart Cities, 2(2), 135-152. DOI: 10.3390/ smartcities2020010 